\title{
Investigation on HSLA Steel Weld Metal Heterogeneous Microstructure
}

\author{
Mir Mostafa Hosseinioun ${ }^{1 *}$, Ghazal Moeini $^{2}$ and Carsten Konke ${ }^{2}$ \\ ${ }^{1}$ Department of Marine Engineering, Iran \\ ${ }^{2}$ Bauhaus Universität Weimar, Germany
}

*Corresponding author: Mostafa Hosseinioun, Department of Marine Engineering, Iran

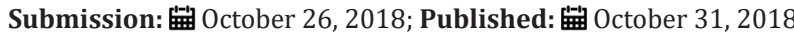

\section{Experiment and Results}

Different HSLA steel Bead on plate and Butt welds were produced by MMAW process with E7018 LT and E 8018 electrodes [1-3]. The microstructural study results are as follows:

1. Flat welding position, plates $6.3 \mathrm{~mm}$ thickness with lower heat input, fast cooling rates, shorter available time distance within initial austenite temperature range, the weld microstructure consisted of pro eutectoid ferrite and inter granular acicular ferrite within pro eutectoid (prior) austenite grains. EPMA study revealed $\mathrm{Mn}$ and to some extend Si concentration were in their interfaces boundary region. The (segregated) alloying elements were not directly corresponding with each other's. It shows that during pro eutectoid ferrite formation and its consequence growth, adjacent to prior austenite grain, $\mathrm{Mn}$ and possibly Carbon as an austenite stabilizer, have diffused out from newly formed pro eutectoid ferrite phase, they set up a diffusion profile with the rest of the proeutectoid austenite, surrounding the pro eutectoid grain interface. Furthermore, the intergranular acicular ferrite grain boundaries in proeutectoid austenite grains were covered with dark etching films (layer) constituents. Therefore; higher welding speed, lower heat input, specific high cooling rate could create proeutectoid austenite grains thermodynamically with new saturating condition, suitable for inter granular acicular ferrite formation within prior austenite grains with diffusion control solid phase transformation.

2. Vertical up welding position plates $6.3 \mathrm{~mm}$ thickness They had higher heat input, slower cooling rate and consequently longer available time distance within initial austenite temperature range. Their weld microstructure consisted of the Initial austenite grains decomposition to other high temperature dark etching microstructural constituent phase, i.e. lamellar type structural component. This could be due to the longer available time distance as well as suitable kinetic condition in initial austenite grains. Typical optical microscopy results revealed some pattern like the prior austenite grains with randomly dispersed ferrite grain, with no dark etching constituent's films (layer) covered at their grain boundaries interface. EPMA study revealed there were random Mn distribution map throughout the matrix. There were some striations present in ferrite grains, which possibly could be formed by shear mechanism from the solidification and phase transformation state. The possible strain produced by the shear transformation activates many adjacent nuclei so that ferrite type plates form side by side type structure. The interior of some grains consisted of lamellar component type structure i.e. feathery lath type structure, forming side by side filling the interior of the grain. However, in some prior austenite grains there were also isolated dispersed fine ferrite type structure.

3. plateX, $12.7 \mathrm{~mm}$ thickness, Single run weld. Microstructural studies revealed the proeutectoid ferrite grains were surrounding prior austenite grain. In some cases, dispersed ferrite grains were within pro-eutectoid ferrite region. The prior austenite grains interior had transformed to dark etching intergranular acicular ferrite. Direct extraction carbon replica (TEM) results revealed proeutectoid ferrite and intergranular acicular ferrite structure. The intergranular acicular ferrites were separated by grain boundaries which were covered by a cluster or film (partition) of a dark etching constituent. EPMA studies revealed fine second phase particles (less than $1 \mu \mathrm{m}$ ) consisting of different alloying elements. Thin foil study results by TEM study revealed various ferrite morphologies, some with high dislocation density, which were not necessarily within the ferrite grains but mostly in the grain boundary regions. The grain boundaries were free of particles; however, they were present within the ferrite grains.

4. Y, plate, $12.7 \mathrm{~mm}$ thickness, single run weld. Microstructural studies revealed a combination of aggregated fine interlocking ferrite grains, similar to intergranular ferrite and some coarser ferrite grains as well as side plate type microstructures. Direct extraction carbon replica results showed the presence of heterogeneous ferrite, some within the packets of coarser grains. Their grain boundaries did not appear as a continuous dark etching constituent film, but with dark etching constituent particles (possibly carbide). It appears that, at first the austenite transformed to disperse ferrite and then particles were precipitated on the available ferrite grain boundaries rather than distributing the same within the matrix grains. However; austenite did not transform to pro-eutectoid ferrite and intergranular acicular ferrite type structures similar to the weld X. 
5. Single run welds, $8 \mathrm{~mm}$ thickness plate, produced by E8o18 electrode (higher Ni content) revealed:

A. flat welding position, there were: (i) Dispersed pro eutectoid ferrite (ii) dark etching microstructural constituent with no clear ferrite grain boundaries in matrix (iii) no intergranular acicular ferrite (iv) with the nucleation of some fine recrystallized ferrite grains.

B. Vertical up welding position, there were: (i) dispersed dark etching component type micro structural feature, (ii) some feathery lath type structure.

6. Multirun welds, $12.7 \mathrm{~mm}$ thickness plate.

A. In the last run fusion and heat affected zone interface the solidification is phenomenon of epitaxial growth structure. However, in previous weld run there was neither epitaxial growth nor typical refined grains structure which is defined by Dube classification and IIW modification.

B. In the inter run layer, there were heterogeneous ferrite grains, internal defects, porosities, and precipitated micro alloying elements which are the cause of weld metal toughness deterioration. Therefore, this is essentially because of micro structural variation which is due to. (i) applied thermal history and slower cooling rate, (ii) Transmitted thermal stresses (iii) various weld dilution with parent plate and previous weld runs, (iv) inherited weld metallurgical characteristics from different rolling condition and parent plate specification.

C. Thus, there is a need for re-evaluate (i) HSLA steel multirun weld microstructure definition, (ii) codes, (iii) standards for tolerance acceptance for weld metal microstructural defects, their welding procedure specification (WPS) with a new comprehensive one for as-cast, inter-run region and previous weld runs microstructural feature.
7. First run refined region. Weld metal fine ferrite grain size in refined region microstructure was about seven micron. However; there was some inconsistency in grain size measurement in comparison with some welds root runs due to the presence of heterogeneous fine and coarse ferrite grains microstructure.

\section{Conclusion and Suggestion for Further Work}

1. The mechanism of intergranular acicular ferrite formation in prior austenite grains is a diffusion control solid phase transformation.

2. In vertical up welding position, with consequent longer cooling rate time, the delay time in austenite transformation favoring formation of carbides, and different phase i.e. side plate, lamellar type structural component in HSLA steel weld metal rather than intergranular acicular ferrite.

3. It is necessary to (i) investigate the formation of intergranular ferrite with dark etching grain boundaries films and/ or dark etching ferrite grain boundaries particles in weld metals, (ii) the alloying element effect which are producing grain boundaries precipitated particles in conjunction with depletion of ferrite matrix from certain grain refining alloying elements.

\section{References}

1. Hosseinioun, G Moeini (2016) Acicular ferrite nucleation as a diffusioncontrolled process in high strength low alloyed (HSLA) steel weld metal. Materials Testing 58(10): 848-859.

2. Hosseinioun (2017) An investigation on multi-run metal made of HSLA Steel - Heterogeneous microstructures and mechanical properties: Propose to modify the welding procedure specification. Materials Testing 59(7): 661-672.

3. (2018) $4^{\text {th }}$ International conference on welding and failure analysis of engineering materials.
Creative Commons Attribution 4.0 International License

For possible submissions Click Here
Submit Article

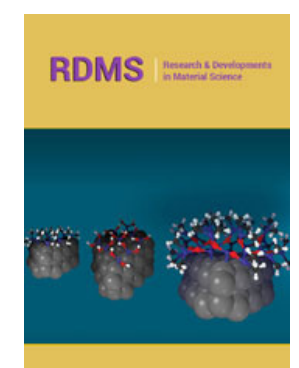

Research \& Development in Material Science

\section{Benefits of Publishing with us}

- High-level peer review and editorial services

- Freely accessible online immediately upon publication

- Authors retain the copyright to their work

- Licensing it under a Creative Commons license

- Visibility through different online platforms 